\title{
Browning of subcutaneous fat and higher surface temperature in response to phenotype selection for advanced endurance exercise performance in male DUhTP mice
}

\author{
J. Brenmoehl ${ }^{1} \cdot$ D. Ohde ${ }^{1} \cdot$ E. Albrecht ${ }^{2} \cdot$ C. Walz ${ }^{1} \cdot$ A. Tuchscherer $^{3} \cdot$ A. Hoeflich $^{1}$
}

Received: 28 January 2016 / Revised: 12 September 2016 / Accepted: 20 September 2016 / Published online: 30 September 2016 (C) The Author(s) 2016. This article is published with open access at Springerlink.com

\begin{abstract}
For the assessment of genetic or conditional factors of fat cell browning, novel and polygenic animal models are required. Therefore, the long-term selected polygenic mouse line DUhTP originally established in Dummerstorf for high treadmill performance is used. DUhTP mice are characterized by increased fat accumulation in the sedentary condition and elevated fat mobilization during mild voluntary physical activity. In the present study, the phenotype of fat cell browning of subcutaneous fat and a potential effect on oral glucose tolerance, an indicator of metabolic health, were addressed in DUhTP mice. Analysis of peripheral fat pads revealed increased brite (brown-in-white) subcutaneous adipose tissues and in subcutaneous fat from DUhTP mice higher levels of irisin and different markers of fat cell browning like T-box transcription factor (Tbx1), PPAR $\alpha$, and uncoupling protein (UCP1) $(P<0.05)$ when compared to unselected controls. UCP1 was further increased in subcutaneous fat from DUhTP mice in response to mild exercise (fourfold, $P<0.05)$. In addition, surface temperature of DUhTP mice was increased when compared to controls indicating
\end{abstract}

Communicated by G. Heldmaier.

A. Hoeflich

hoeflich@fbn-dummerstorf.de

1 Institute for Genome Biology, Leibniz-Institute for Farm Animal Biology (FBN), Wilhelm-Stahl-Allee 2, 18196 Dummerstorf, Germany

2 Institute for Muscle Biology and Growth, Leibniz-Institute for Farm Animal Biology (FBN), Wilhelm-Stahl-Allee 2, 18196 Dummerstorf, Germany

3 Institute for Biometry and Genetics, Leibniz-Institute for Farm Animal Biology (FBN), Wilhelm-Stahl-Allee 2, 18196 Dummerstorf, Germany a physiological effect of increased UCP1 expression. The present study suggests that DUhTP mice exhibit different markers of mitochondrial biogenesis and fat browning without external stimuli. At an age of 43 days, sedentary DUhTP mice have improved metabolic health as judged from lower levels of blood glucose after an oral glucose tolerance test. Consequently, the non-inbred mouse model DUhTP represents a novel model for the identification of fat cell browning mechanisms in white adipose tissues.

Keywords Selection · Browning $\cdot$ Irisin $\cdot$ Subcutaneous fat $\cdot$ Uncoupling protein

\section{Introduction}

The Dummerstorf marathon mouse model DUhTP has been selected over 90 generations for high treadmill performance (Falkenberg et al. 2000) and thus represents a unique model for the study of energy metabolism. In the liver of DUhTP mice increased lipid synthesis has been postulated based on the analysis of hepatic metabolome by current mass spectrometry (Brenmoehl et al. 2013). In the sedentary condition, marathon mice accumulate high amounts of body fat in external depots indicating physiological relevance of lipids for superior endurance exercise performance in DUhTP mice. In fact, recent work revealed that external fat mass in DUhTP mice is highly responsive to physical activity because voluntary exercise in running wheels completely abolished the obese phenotype of DUhTP mice (Brenmoehl et al. 2015). In subcutaneous fat from DUhTP mice, PGC1- $\alpha$ and mitochondrial DNA content were increased and it was speculated that fat cell browning may occur in subcutaneous white adipocytes (Brenmoehl et al. 2015). It is known that brite 
adipocytes, converted from white adipocytes, exhibit properties of brown adipocytes like expression of UCP1 and a proposed mechanism for the induction of browning in WAT may occur by irisin derived from muscle after contraction (Bostrom et al. 2012) or from the fat independent of physical exercise (Roca-Rivada et al. 2013). A number of studies has demonstrated that the addition of exogenous irisin or irisin precursors (FNDC5) induced browning of white fat cells both in rodent (Zhang et al. 2014; Bostrom et al. 2012) and in human white fat cells (Zhang et al. 2016; Huh et al. 2014; Lee et al. 2014). Fat cell browning in response to irisin treatment further induced cellular thermogenesis in mature human white fat cells (Zhang et al. 2016). Because irisin may represent an early marker of fat cell browning and thermogenesis, it may have the potential as a novel anti-obesity drug (Bostrom et al. 2012) or in a more general view could be seen as an attractive tool for the manipulation of energy metabolism in vivo.

Interestingly, after acute exercise, higher levels of irisin have been found in muscle extracts and in serum of marathon mice (DUhTP) long-term selected for endurance exercise (Brenmoehl et al. 2014) supporting the idea that irisin may act as an endogenous effector of energy metabolism.

The aim of the present work is to determine if the marathon mouse model DUhTP is a natural model for the analysis of adipose browning in the presence of elevated FNDC5/irisin expression. To accomplish this, we measured FNDC5/irisin expression and content of selected tissues, UCP1 content, and skin temperature as a surrogate for core temperature both in DUhTP mice and in unselected controls.

\section{Materials and methods}

\section{Animals}

All in vivo experiments were performed in accordance with national and international guidelines and were approved by our internal institutional review board. In this study, on one hand, a non-inbred mouse line that has been generated by selection over 90 generations for high treadmill performance (DUhTP) (Falkenberg et al. 2000) and on the other control mice (DUC) that had been generated from the identical base population without phenotype selection was used (Dietl et al. 2004). The males were housed under controlled environmental conditions in a semi-barrier system with a 12-h light-12-h dark cycle (room temperature $=22.5$ $\pm 0.2{ }^{\circ} \mathrm{C}$, humidity $=50-60 \%$ ) as described in (Brenmoehl et al. 2013). At an age of 49 days, DUhTP mice and controls were kept either in home cages with running wheels (RW) ( $d=33.4 \mathrm{~cm}$; Tecniplast, Hohenpeißenberg,
Germany) to assess physical activity over a period of 3 weeks ( $n=10$ per group) or in cages without RW as controls ( $n=10$ per group). At 70 days of age, mice were fasted overnight and killed by decapitation to collect serum samples. Tissues were weighted (summary in Table 1), snap-frozen in liquid nitrogen, and stored at $-70{ }^{\circ} \mathrm{C}$ for subsequent analysis. In parallel, mice $(n=9$ per group) were analyzed under temperature conditions of husbandry at $22{ }^{\circ} \mathrm{C}$ for surface temperature using an infrared camera (Testo 881; Testo AG, Lenzkirch, Germany).

\section{Oral glucose tolerance test}

Oral glucose tolerance tests (oGTT) were performed in mice at an age of 43 and 71 days, essentially as described before (Renne et al. 2013). In brief, glucose was applied to overnight fasted mice (43 days: $n=20 ; 71$ days: $n>5$ per group) in an oral dose of $1 \mathrm{~g}$ glucose $/ \mathrm{kg}$ body weight dissolved in tap water and concentrations of blood glucose were assessed before and 10, 30, 60, and $120 \mathrm{~min}$ after the oral glucose bolus. Glucose concentrations were analyzed using a glucometer (Roche, Penzberg, Germany).

\section{Quantitative real-time PCR}

Expression of different mRNA transcripts in subcutaneous fat samples $(\mathrm{n}=7)$ was analyzed in triplicates as described previously (Brenmoehl et al. 2014, 2015). Primers used are mTbx1-forw: ggcaggcagacgaatgttc, mTbx1-rev: ttgtcatctacgggcacaaag, UCP1-forw: ggcctctacgactcagtcca, UCP1-rev: taagccggctgagatcttgt, Tcf21-forw: cattcacccagtcaacctga, Tcf21-rev: ttccttcaggtcattctctgg, Fndc5-forw: caacgagcccaataacaaca, Fndc5-rev: agaaggtcetctcgcattctc. Different housekeeping genes (Brenmoehl et al. 2015) were tested to identify the HKG with comparable Crossing point $(\mathrm{Cp})$-values $\left(\mathrm{Cp}_{\mathrm{Rplp} 2}\right.$ : DUhTP: $24.45 \pm 1.17$; DUC: $25.80 \pm 1.03)$ to normalize expression of $T b x l$ and $U c p l$.

\section{Immunoblotting}

Western immunoblotting was performed as described previously (Brenmoehl et al. 2014). Equal loading of the gels and proper transfer of the proteins to the membranes were verified by Coomassie Blue staining according to standard procedures (Taylor et al. 2013). Expression of UCP1 (sc6529, Santa Cruz, Heidelberg, Germany), irisin (A0017001-100; Bio Trend, Cologne, Germany), and FNDC5 (AP8746b; Abgent, San Diego, CA, USA) in all ten animals per group were studied by Western immunoblotting. Western immunoblots were repeated at least three times. Thereby, samples were determined in different order to avoid position effects while blotting. 
Table 1 Body and tissue weights of male mice long-term selected for high treadmill performance (DUhTP) and unselected controls (DUC) at an age of 70 days as published before (Brenmoehl et al. 2015)

\begin{tabular}{|c|c|c|c|c|c|c|c|c|c|}
\hline & $n$ & DUhTP & DUhTP-RW & $P$ & DUC & DUC-RW & $P$ & $\begin{array}{l}P \text { (DUhTP } \\
\text { vs DUC) }\end{array}$ & $\begin{array}{l}P \text { (DUhTP- } \\
\text { RW vs DUC- } \\
\text { RW) }\end{array}$ \\
\hline Body mass (g) & 10 & $32.18 \pm 1.02$ & $31.25 \pm 0.87$ & 0.4925 & $35.18 \pm 0.67$ & $34.65 \pm 0.79$ & 0.6125 & 0.0191 & 0.0066 \\
\hline Lean body mass (g) & 10 & $20.89 \pm 1.76$ & $20.5 \pm 1.78$ & 0.7529 & $23.56 \pm 1.44$ & $23.45 \pm 1.61$ & 0.8702 & 0.0025 & 0.0007 \\
\hline Body length (cm) & 10 & $10.04 \pm 0.12$ & $9.93 \pm 0.11$ & 0.4907 & $10.44 \pm 0.10$ & $10.42 \pm 0.09$ & 0.8845 & 0.0135 & 0.0014 \\
\hline $\begin{array}{l}\text { Musculus rectus } \\
\text { femoris }(\mathrm{g})\end{array}$ & 10 & $0.37 \pm 0.01$ & $0.38 \pm 0.01$ & 0.2969 & $0.39 \pm 0.01$ & $0.36 \pm 0.01$ & 0.0795 & 0.1378 & 0.1767 \\
\hline $\begin{array}{l}\text { Musculus rectus } \\
\text { femoris }(\%)\end{array}$ & 10 & $0.0114 \pm 0.00$ & $0.0122 \pm 0.00$ & 0.0372 & $0.0111 \pm 0.00$ & $0.0104 \pm 0.00$ & 0.0862 & 0.3829 & 0.0004 \\
\hline Liver mass (g) & 10 & $1.81 \pm 0.07$ & $1.76 \pm 0.08$ & 0.6301 & $1.94 \pm 0.06$ & $1.82 \pm 0.06$ & 0.1513 & 0.1571 & 0.5192 \\
\hline Liver mass (\%) & 10 & $0.0561 \pm 0.00$ & $0.0561 \pm 0.00$ & 0.9855 & $0.0552 \pm 0.00$ & $0.0525 \pm 0.00$ & 0.1388 & 0.5363 & 0.0758 \\
\hline Subcutaneous fat (g) & 10 & $0.36 \pm 0.03$ & $0.22 \pm 0.03$ & 0.0012 & $0.20 \pm 0.01$ & $0.18 \pm 0.02$ & 0.4910 & 0.00003 & 0.2448 \\
\hline Subcutaneous fat (\%) & 10 & $0.0112 \pm 0.00$ & $0.0065 \pm 0.00$ & 0.0002 & $0.0056 \pm 0.00$ & $0.0053 \pm 0.00$ & 0.6095 & 0.00001 & 0.1495 \\
\hline Epidymal fat (g) & 10 & $0.33 \pm 0.03$ & $0.23 \pm 0.03$ & 0.0145 & $0.28 \pm 0.03$ & $0.20 \pm 0.02$ & 0.0183 & 0.2122 & 0.2718 \\
\hline Epidymal fat (\%) & 10 & $0.0102 \pm 0.00$ & $169 \pm 0.00$ & 0.0025 & $179 \pm 0.00$ & $156 \pm 0.00$ & 0.0195 & 0.0320 & 0.1383 \\
\hline Perinephric fat (g) & 10 & $0.16 \pm 0.02$ & $0.08 \pm 0.01$ & 0.0020 & $0.09 \pm 0.01$ & $0.06 \pm 0.01$ & 0.0086 & 0.0035 & 0.2327 \\
\hline Perinephric fat $(\%)$ & 10 & $0.0049 \pm 0.00$ & $0.0021 \pm 0.00$ & 0.0002 & $0.0025 \pm 0.00$ & $0.0017 \pm 0.00$ & 0.0083 & 0.0003 & 0.2122 \\
\hline Brown fat $(\mathrm{g})$ & 10 & $0.09 \pm 0.01$ & $0.07 \pm 0.00$ & 0.0191 & $0.06 \pm 0.00$ & $0.06 \pm 0.00$ & 0.7512 & 0.0006 & 0.1189 \\
\hline Brown fat $(\%)$ & 10 & $0.0027 \pm 0.00$ & $0.0022 \pm 0.00$ & 0.0361 & $0.0017 \pm 0.00$ & $0.0017 \pm 0.00$ & 0.8656 & 0.00005 & 0.0103 \\
\hline
\end{tabular}

Mice were kept in cages with running wheels (RW) or without. Total body lean mass was analyzed by dual energy X-ray absorptiometry. Values are presented as mean \pm SE. Significant group effects $(P)$ are indicated in bold letters (\%: normalized by body weight)

\section{Immunohistochemical staining in adipose tissue}

In addition to standard hematoxylin/eosin (H/E) staining, immunohistochemistry was applied for UCP1 and C/EBP $\beta$ detection on $12 \mu \mathrm{m}$ thick frozen tissue sections (2-3 randomly selected mice per group) using antibodies against either UCP1 (1:100, sc-6529, Santa Cruz) for $1 \mathrm{~h}$ at room temperature or C/EBP $\beta$ (1:100, sc-150, Santa Cruz) for $2 \mathrm{~h}$ at room temperature in a humidity chamber similar to previously described procedure (Albrecht et al. 2015a). Specific binding was detected with fluorescence-labeled secondary antibodies (MFP 488 rabbit anti- goat IgG for UCP1 and MFP 590 goat anti-rabbit IgG for C/EBP $\beta$, MoBiTec, Goettingen, Germany). All sections were counterstained with $1 \mu \mathrm{g} / \mathrm{ml}$ Hoechst 33258 (Sigma-Aldrich, Munich, Germany). Immunofluorescence was visualized with a Nikon Microphot SA fluorescence microscope (Nikon Instruments Europe B.V., The Netherlands) and an image analysis system equipped with $\mathrm{CELL}^{\wedge} \mathrm{F}$ image analysis software and a CCD-12 high resolution color camera (OSIS, Münster, Germany). The selected H/E images are representative in any case for a region of typical unilocular white adipocytes and a region of multilocular adipocytes. Fluorescence images represent a region of multilocular cells to illustrate protein expression typical for either heat producing or differentiating adipocytes. Subcutaneous fat samples were cryosectioned ( $25 \mu \mathrm{m}$ thick) using a Leica CM3050 S (Leica, Bensheim, Germany) cryostat microtome. Sections were stained with hematoxylin/eosin (H/E; hematoxylin: Dako, Glostrup, DK; eosin: Chroma Gesellschaft, Münster, Germany) and embedded with RotiHistokit (Roth, Karlsruhe, Germany). Adipocyte size was measured using the interactive measurement module of an image analysis system equipped with an Olympus BX43 microscope (Olympus, Hamburg, Germany), an UC30 color camera (Olympus) and $\mathrm{CELL}^{\wedge} \mathrm{D}$ image analysis software (OSIS, Munster, Germany). About 300 adipocytes per sample were randomly selected and measured, after following the contour using the interpolating polygon function.

\section{Statistical analysis}

The data analysis was performed using SAS software (Version 9.4 for Windows, SAS Institute Inc., Cary, NC, USA). Descriptive statistics and tests for normality were calculated with the UNIVARIATE procedure of Base SAS software (SAS Institute Inc. 2013. Base SAS ${ }^{\circledR} 9.4$ Procedures Guide, Second Edition. Cary, NC: SAS Institute Inc.). Data considered approximately normal were analyzed by ANOVA using the GLIMMIX procedure of SAS/STAT 
software (SAS Institute Inc. 2013. SAS/STAT ${ }^{\circledR} 13.1$ User's Guide. Cary, NC: SAS Institute Inc.). The ANOVA model for the 70 days data included the fixed factors line (levels: DUC, DUhTP), group (levels: co, RW), and the interaction line $\times$ group. Homogeneity of covariance parameters across groups was tested for all ANOVA models. In addition, least-squares means (LSM) and their standard errors (SE) were computed for each fixed effect in the models, and all pairwise differences of LS-means were tested by the Tukey-Kramer procedure. Effects and differences were considered significant if $P<0.05$. Glucose levels in response to oral glucose application were further analyzed by repeated measurements ANOVA provided by the BASE SAS software package.

\section{Results}

\section{Irisin in subcutaneous adipose tissue}

Previously, expression of FNDC5 protein in muscles and abundance of irisin in serum of DUhTP mice was demonstrated (Brenmoehl et al. 2014). Now expression of irisin and FNDC5 was analyzed in active and sedentary DUhTP and control mice. Both mouse lines voluntarily used running wheels present in their home cages to a similar extent (DUhTP: $3935 \pm 1719$; DUC $3913 \pm 1181 \mathrm{~m} /$ day). A comparison of FNDC5 and irisin between both sedentary mouse lines revealed abundant but unchanged levels of muscular FNDC5 (Fig. 1a) but higher levels of irisin (Fig. 1b) in serum of DUhTP mice ( fourfold, $P<0.05$ ). Physical activity had no influence on FNDC5 or irisin levels. Indeed, very high concentrations of irisin were detected in subcutaneous adipose tissue of DUhTP mice (Fig. 1c). In contrast to controls, sedentary and active DUhTP mice showed over twofold increased irisin levels; FNDC5 protein was barely detectable in subcutaneous adipose tissue and showed no clear differences.

\section{Elevated browning in subcutaneous fat from DUhTP mice}

Subcutaneous fat dissected from DUhTP mice of both treatment groups appeared darker when compared to unselected control mice, which suggested differential browning in DUhTP and DUC mice. Histological examination revealed clustered formation of smaller multilocular adipocytes (brite fat cell) and larger unilocular adipocytes (white fat cell) in tissue sections from subcutaneous fat of both mouse lines at an age of 10 weeks (Fig. 2). Clustered appearance of white and brite fat cells was also observed in 90-dayold mice of both genetic groups. Examination of the tissue sections indicated larger areas covered by brite fat cells in
DUhTP versus DUC mice. In white adipocytes, histological parameters (area, diameter, and Feret diameter) were unaffected by genetic group of voluntary physical activity (data not shown). To describe the differential phenotype of fat cell browning, biomarkers of brown, white, and brite fat cells were assessed in subcutaneous fat (Fig. 3a). Tbx1 mRNA expression was significantly increased in DUhTP mice $(56 \% ; P<0.05)$ compared to unselected controls. Physical activity in DUhTP had no significant effect on mRNA expression of the brite adipose tissue marker Tbx 1 $(22 \%$, n.s.). As expected, white adipose tissue marker transcription factor 21 (Tcf21) was barely expressed in sedentary DUhTP mice when compared to control mice but the differences between both mouse lines reached no statistical significance because of high individual variability. Transcription factor PPAR $\alpha$ was also elevated in the subcutaneous fat of active and sedentary DUhTP mice in contrast to control animals (17-fold; $P<0.005$ and 21-fold; $P<0.05$, respectively). Downstream expression of BAT-marker Ucp1 was increased in subcutaneous fat of DUhTP mice as well (50-fold; $P<0.005)$. In response to activity, expression of Ucp1 further increased threefold $(P<0.05)$. In controls, expression of Tbx1, PPAR $\alpha$, and Ucp1 were unaffected by physical activity.

Higher expression of UCP1 in DUhTP mice in subcutaneous fat was present also on the protein level as demonstrated by Western immunoblotting (Fig. 3b). Compared to sedentary DUC mice, UCP1 was 7.3-fold increased in sedentary DUhTP mice. Moderate voluntary activity for 3 weeks resulted in a further 4.2-fold higher protein expression in subcutaneous fat of DUhTP mice when compared to non-exercised controls. Higher protein levels of UCP1 were further demonstrated by immunohistochemistry. Cryostat sections of subcutaneous adipose tissue of sedentary and physical active DUhTP mice displayed areas of multilocular adipocytes. These areas stained massively for UCP1, while in comparable sections of control mice, only weak UCP1 protein expression was detectable (Fig. 3c). Multilocular adipocytes in control mice could be confirmed as differentiating adipocytes with positive staining for CCAAT/enhancer-binding protein beta $(\mathrm{C} / \mathrm{EBP} \beta)$. Only few $\mathrm{C} / \mathrm{EBP} \beta$-positive adipocytes were observed in UCP1stained regions of DUhTP mice.

UCP1 is known to uncouple ATP production leading to enhanced energy production, allowing small animals to better tolerate cold (Himms-Hagen 1970). As an indirect and noninvasive method to determine UCP1 activity, heat production indicated by change in surface temperature was measured in both mouse lines using an infrared camera. It was asked if the increased UCP1 expression in subcutaneous fat correlates with an elevated surface temperature at $22{ }^{\circ} \mathrm{C}$ room temperature. In fact, DUhTP mice showed a significantly higher surface temperature $\left(+1^{\circ} \mathrm{C} ; P<0.005\right)$ 

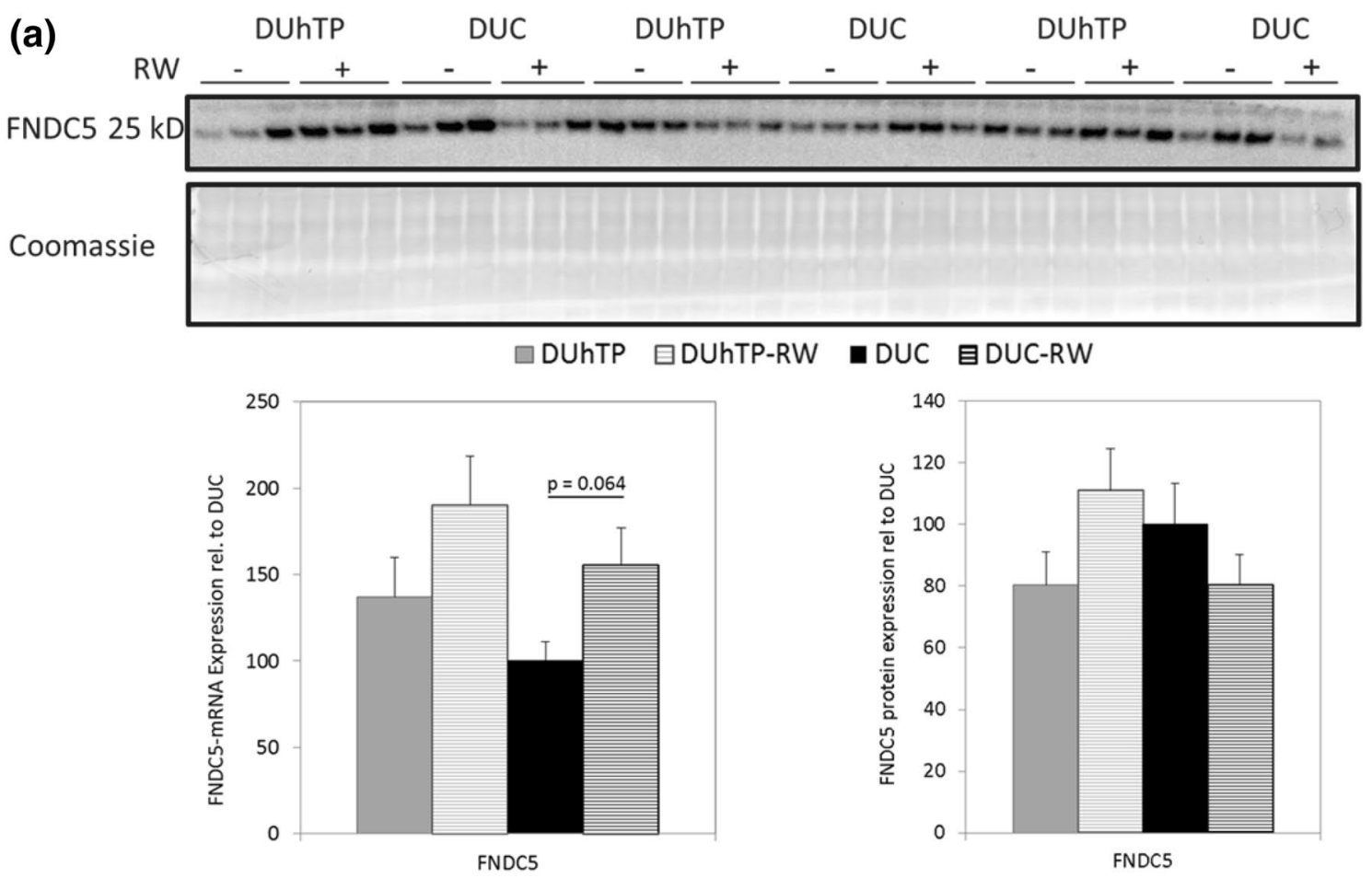

(b)
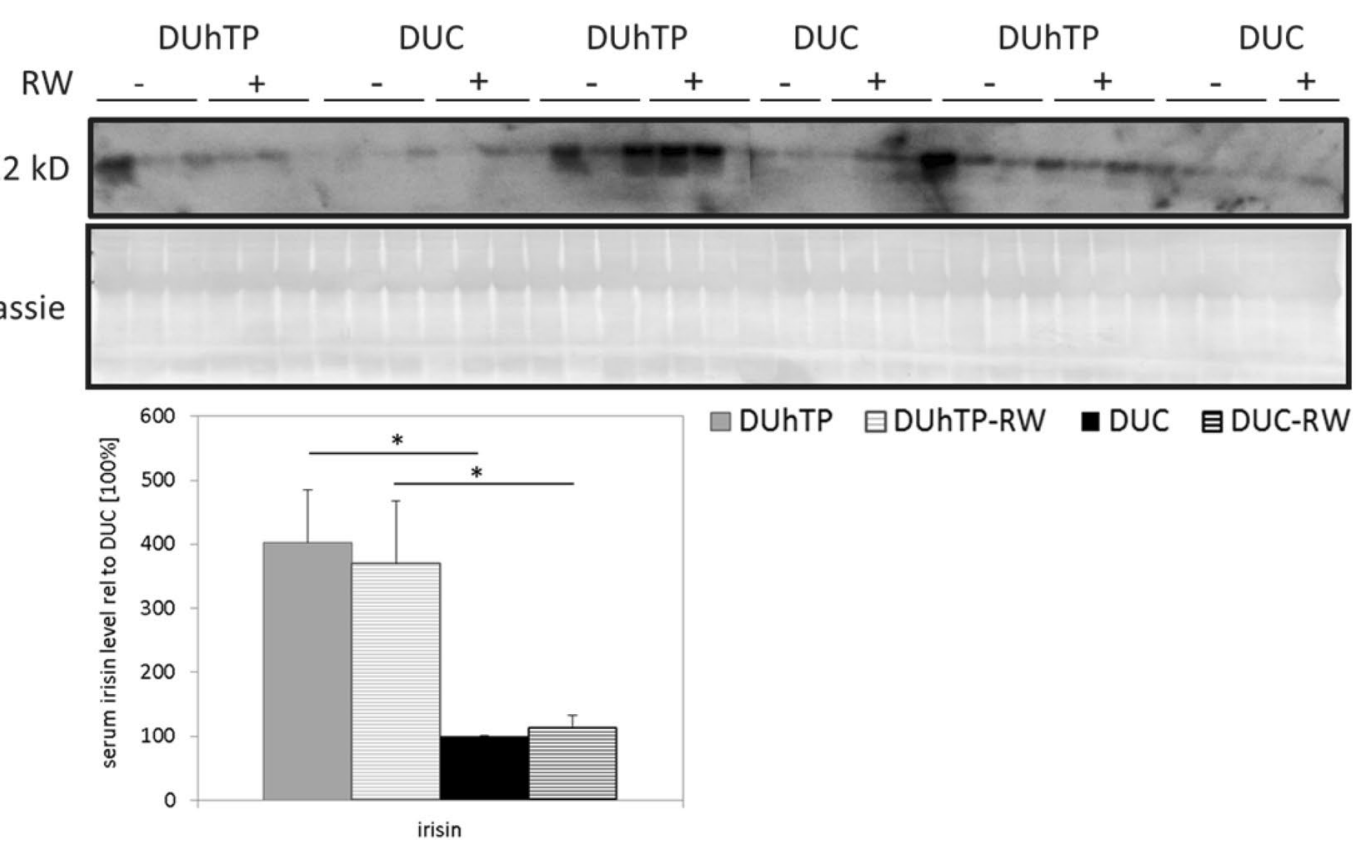

$\square$ DUhTP $\quad$ DDUhTP-RW $\square$ DUC ODUC-RW

Fig. 1 Effect of voluntary physical activity (RW) on levels of a FNDC5 in muscles, $\mathbf{b}$ irisin in serum and $\mathbf{c}$ FNDC5 and irisin in subcutaneous adipose tissue from DUhTP and DUC mice. Analysis of FNDC5-mRNA expression was performed by quantitative real-time PCR and normalized to expression of HKG Rplp2. Protein analysis was performed by Western immunoblotting. Protein expression was quantified by densitometry and normalized for the Coomassie blue signal. All data are expressed in relation to the expression level of sedentary unselected controls (DUC) with no access to RW. Values are mean $\pm \mathrm{SE} ; * P<0.05, * * P<0.005$ 


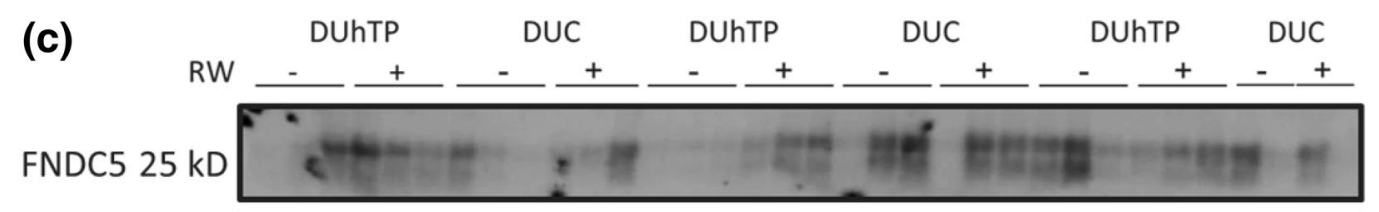

Irisin 12 kD

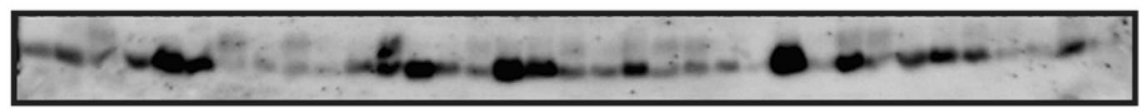

Coomassie
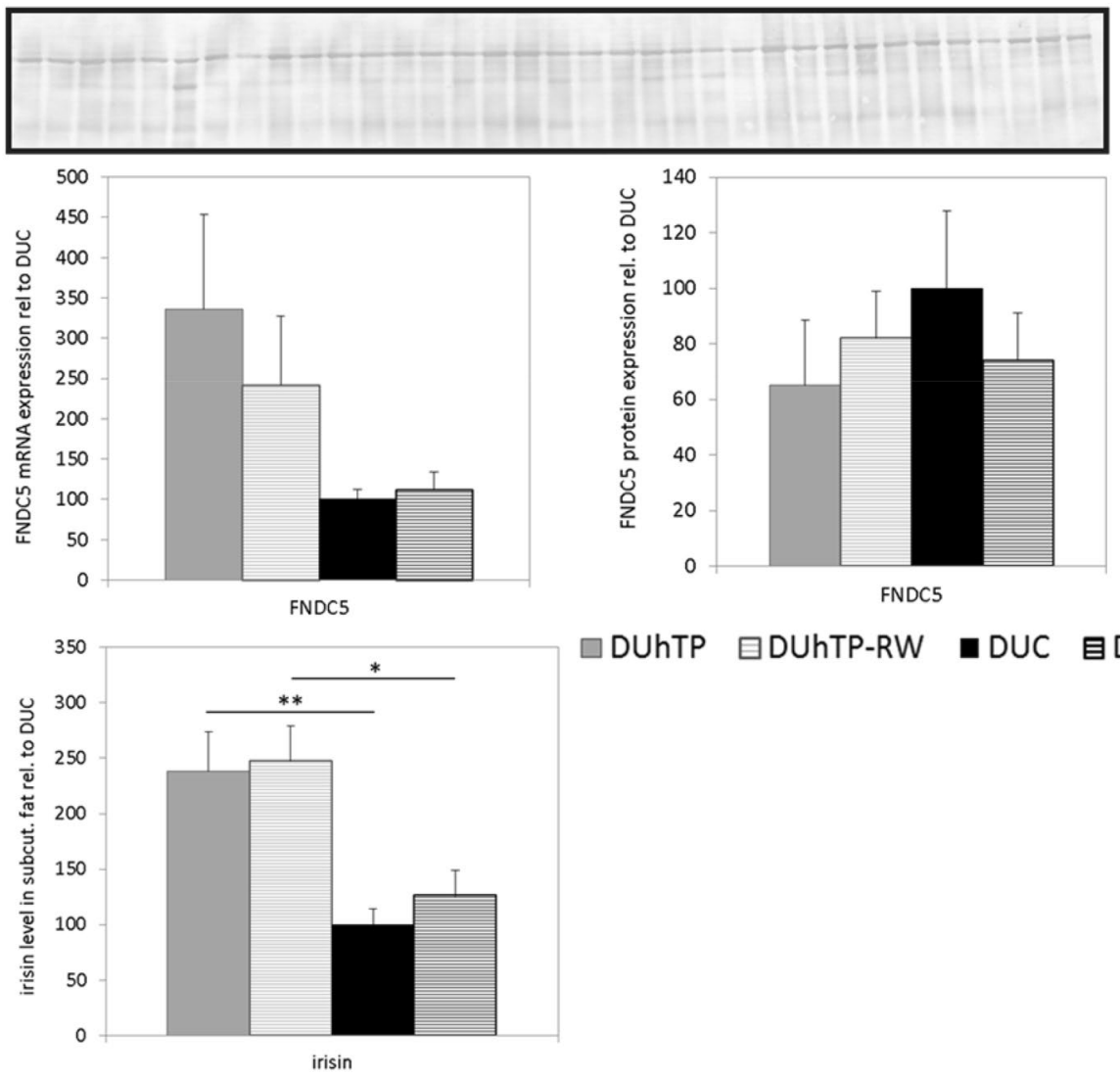

$\square$ DUhTP 目DUhTP-RW שDUC 目DUC-RW

Fig. 1 continued

than control mice (Fig. 4), but differences between active and sedentary littermates were not found.

\section{Better oral glucose tolerance in DUhTP mice}

At an age of 43 days, male DUhTP mice had lower blood glucose levels before and after oral application of glucose (Fig. 5a) at all time points assessed $(P<0.01)$. Lower blood glucose levels were not found in elder DUhTP mice at an age of 71 days (Fig. 5b). However, voluntary physical activity over a period of 3 weeks in DUhTP mice significantly reduced blood glucose $(P<0.05)$. The areas under curve of oral glucose levels after oral glucose tolerance tests in DUhTP mice and unselected controls were statistically not significantly different (data not shown). However, repeated measurement ANOVA revealed a significant interaction between the time of glucose testing and mouse line $(P<0.05)$.

\section{Discussion}

Irisin has been identified as an effector of fat cell browning and thermogenesis by the induction of UCP1 (Bostrom et al. 2012). In addition, irisin effects on carbohydrate and lipid metabolism also have been provided for the liver (Mo et al. 2016) suggesting broader effects on energy metabolism. Our marathon mouse model DUhTP, established by long-term selection for high treadmill performance, is characterized by increased hepatic lipogenesis on one hand and peripheral obesity on the other, if compared to unselected control mice (DUC) (Brenmoehl et al. 2013). For the sake of clarity, we included Table 1 in our manuscript providing published data on increased fat accretion in DUhTP mice (Brenmoehl et al. 2015). Notably, in DUhTP also irisin concentrations were found being increased in skeletal muscle and plasma (Brenmoehl et al. 2014). To establish 

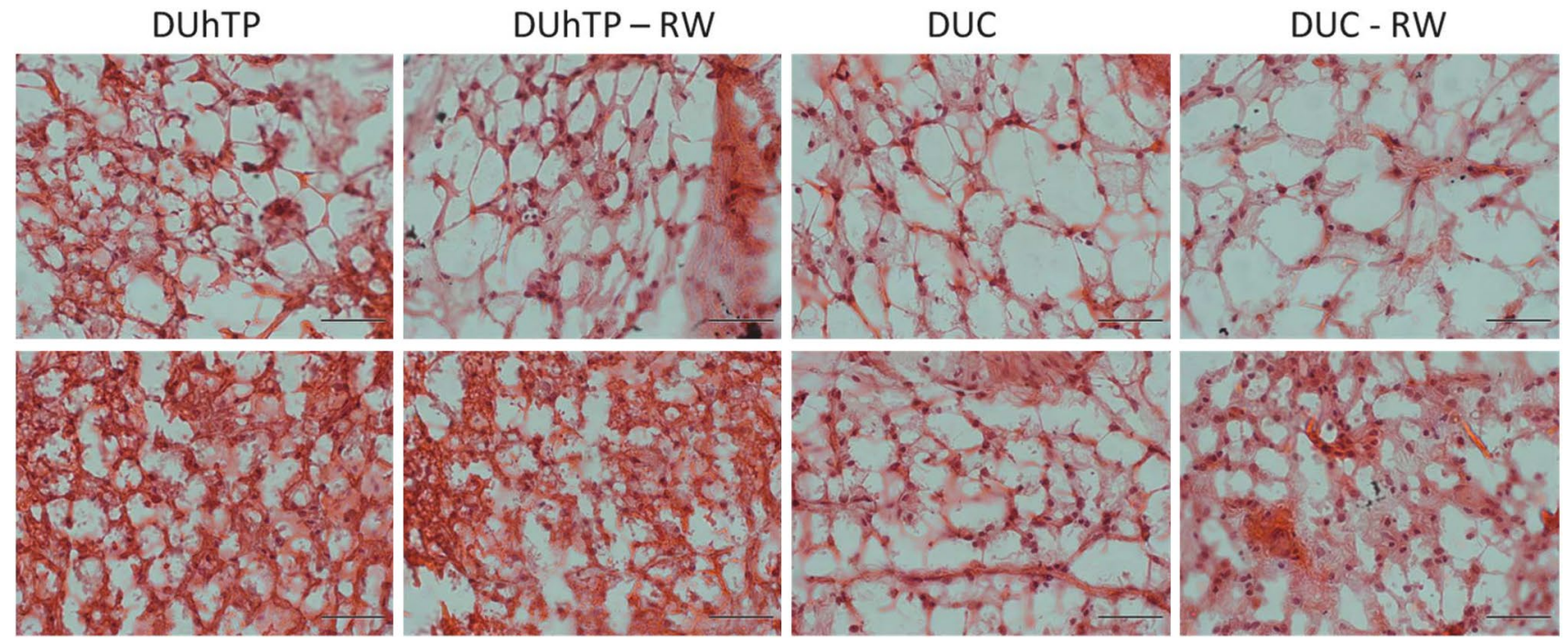

Fig. 2 Hematoxylin/Eosin staining of subcutaneous adipose tissue from sedentary and physical active (-RW) male DUhTP and DUC mice, respectively. Upper set of pictures displays areas of white adipocytes and lower pictures show area with clusters of brite adipocytes. Scale bar $50 \mu \mathrm{m}$

DUhTP mice as an in vivo-relevant and polygenic model of irisin actions, we tested current hypotheses in DUhTP mice. We therefore assessed known effects of irisin in subcutaneous fat and investigated fat cell morphology, browning, UCP1 expression, and thermogenesis in our experimental system. Finally we asked if higher irisin expression in DUhTP also correlated with improved metabolic health.

Adipose tissue of DUhTP mice showed more multilocular adipocytes than DUC mice, with no obvious effect on white adipocyte histology. Real-time PCR and immunohistochemical analyses revealed lower expression of markers associated with white (C/EBP; Tcf21), brite (Tbx1) and brown adipose tissue (UCP1, PPAR $\alpha$ ) (Escher et al. 2001; Wu et al. 2012) arguing for elevated abundance of brite adipocytes in this fat depot of DUhTP mice already under sedentary conditions. In response to 3 weeks of voluntary exercise, UCP1-expression was further increased in DUhTP mice, whereas in controls, no changes were detectable. High UCP1 abundance in DUhTP and weak expression in control mice were confirmed by immunohistochemistry. Especially UCP1, a known regulator of BAT-dependent thermogenesis (Argyropoulos and Harper 2002) with low-level expression in WAT (Wu et al. 2012), indicates the presence of brite cells in subcutaneous fat. Fat cell browning or enhancement of mitochondrial biogenesis in WAT, respectively, is part of the thermogenic program and is induced and activated by the transcriptional regulator PGC1- $\alpha$ leading to increased expression of FNDC5 and after cleavage of FNDC5 higher circulating levels of irisin
(Bostrom et al. 2012; Handschin and Spiegelman 2008). Recently, a study on PGC1- $\alpha$ in muscles of DUhTP mice after endurance exercise on a treadmill provided increased expression of PGC1- $\alpha$ isoforms 1, 3, and 4 on mRNA level (Brenmoehl et al. 2014). Voluntarily exercised mice only showed alterations of PGC1- $\alpha$ isoform 1 mRNA when compared to sedentary littermates (Brenmoehl et al. 2014). These observations nicely agree with those of Ruas et al., who linked PGC1- $\alpha$ isoform 1 mRNA to endurance performance but isoform 4 to resistance training (Ruas et al. 2012). FNDC5 is highly abundant in muscle, rectum, heart, and pericardium but present also in fat, brain, kidney, and liver, however, with lower abundance (Huh et al. 2012). Here, we assessed FNDC5 and irisin in muscle, serum, and subcutaneous fat of both mouse lines. The existence of FNDC5 in muscle and irisin in serum of DUhTP mice had originally been described using an antibody that was able to detect the irisin band of $12 \mathrm{kDa}$ by Western immunoblotting (Brenmoehl et al. 2014). Also in the present work, this antibody was used. As far as we know, this antiserum is the only one that recognizes recombinant irisin with its correct molecular weight of $12 \mathrm{kDa}$ (Albrecht et al. 2015b). Currently, this antiserum is not available because production and distribution have been halted. As discussed recently, different antibodies or antisera used for western immunoblotting or in ELISA studies revealed a number of bands but none of them corresponded to the correct size of irisin at $\sim 12 \mathrm{kDa}$ (Albrecht et al. 2015b). Instead only FNDC5 was identified by different antisera assessed in the study 
Fig. 3 Effect of voluntary physical activity (RW) on mRNA expression (a) of brite adipose tissue marker Tbx1 (upper left panel), brown adipose tissue marker UCP1 (upper right panel) as well as PPAR $\alpha$ (lower left panel) and white adipose tissue marker Tcf21 (lower right panel) in subcutaneous fat tissue of 10-week male DUhTP and DUC mice $(n=7$ per group). Analysis of mRNA expression was performed by quantitative real-time PCR and normalized to expression of HKG Rplp2. The analysis was performed by Western immunoblotting. Protein expression of UCP1 (b) was quantified by densitometry and normalized for the Coomassie blue signal. $\mathrm{UCP} 1$ (green) and C/EBP $\beta$ protein $(r e d)$ were also analyzed by immunohistochemistry (c) in subcutaneous adipose tissue of 10-week male DUhTP and DUC mice. Cryosections of running wheel (RW) exercised and sedentary mice were immunostained with anti-UCP1 and $\mathrm{C} / \mathrm{EBP} \beta$ primary antibodies and MFP 488 rabbit anti- goat IgG secondary antibody for UCP1 and MFP 590 goat antirabbit IgG for C/EBP $\beta$. Data are presented as mean \pm SE and are expressed relative to the expression level of control mice from line DUC. Significant differences are indicated: $* P<0.05$, $* * P<0.005 ; * * * P<0.0005$ ${ }^{\S} P<0.01(\mathrm{C} / \mathrm{EBP} \beta$ CCAAT enhancer-binding protein beta, Tbx1 T-box transcription factor 1, UCP1 uncoupling protein $1, \operatorname{PPAR} \alpha, \mathrm{pc}$ positive control) (color figure online) (a)
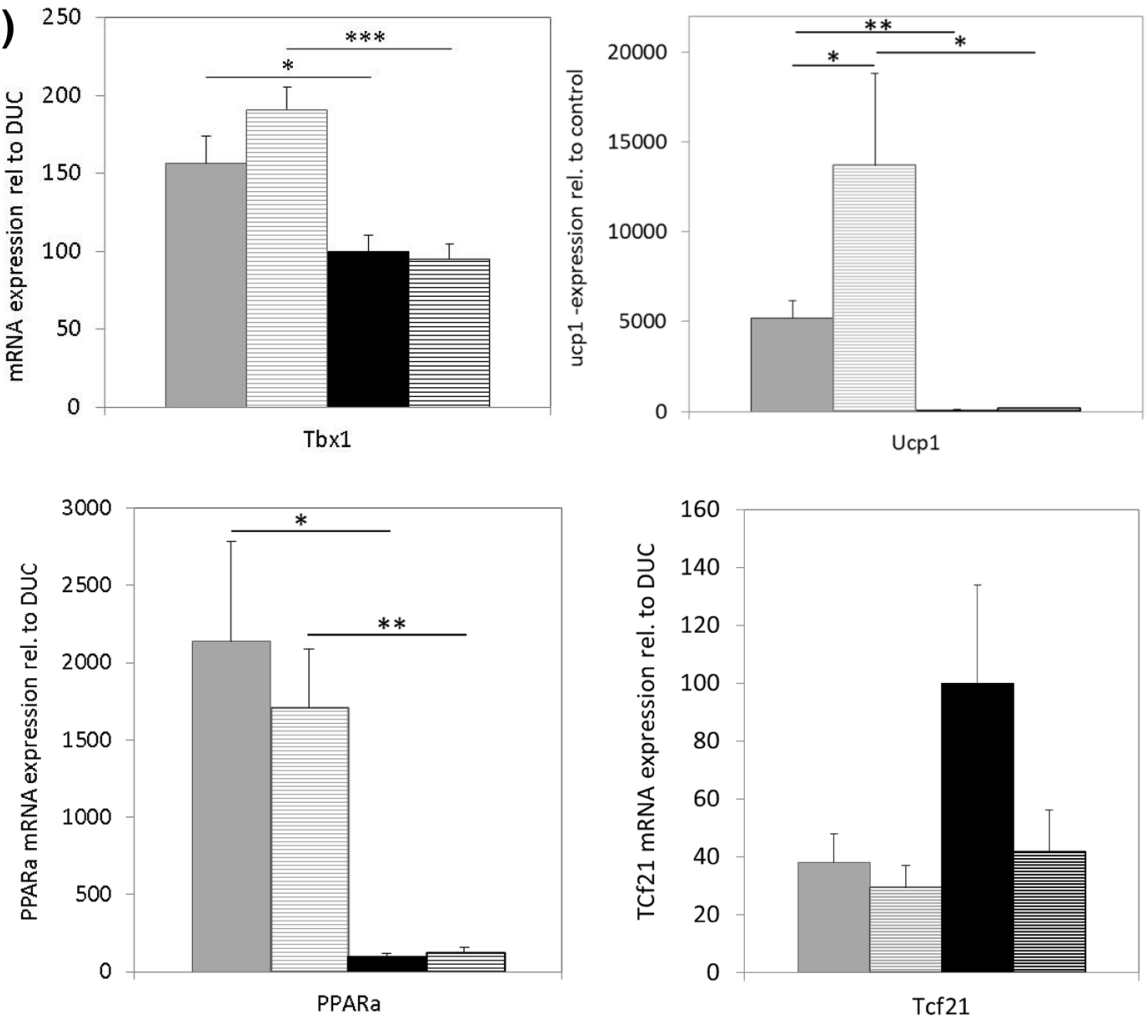

$\square$ DUhTP $\boxminus$ DUhTP-RW $\square$ DUC 目DUC-RW

(b)

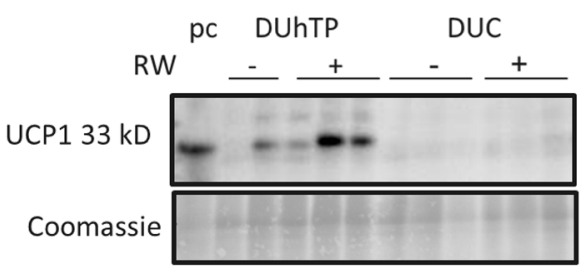

$\square$ DUhTP GDUhTP-RW $\square$ DUC ODDC-RW

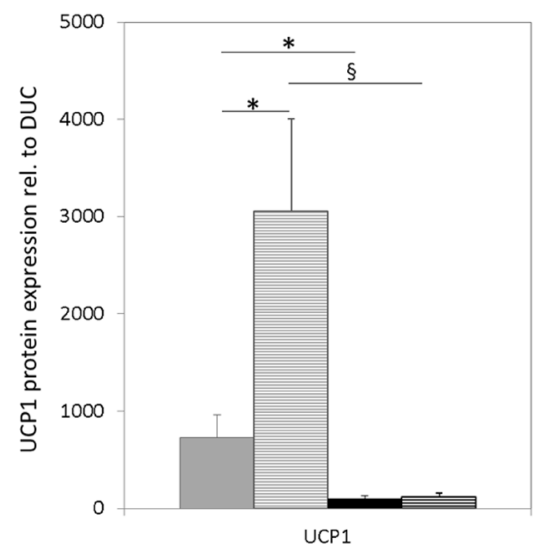

(c)

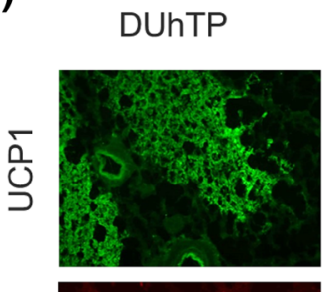

DUhTP-RW

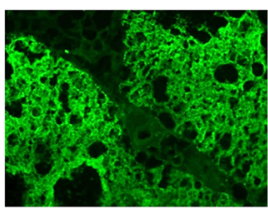

DUC

DUC-RW
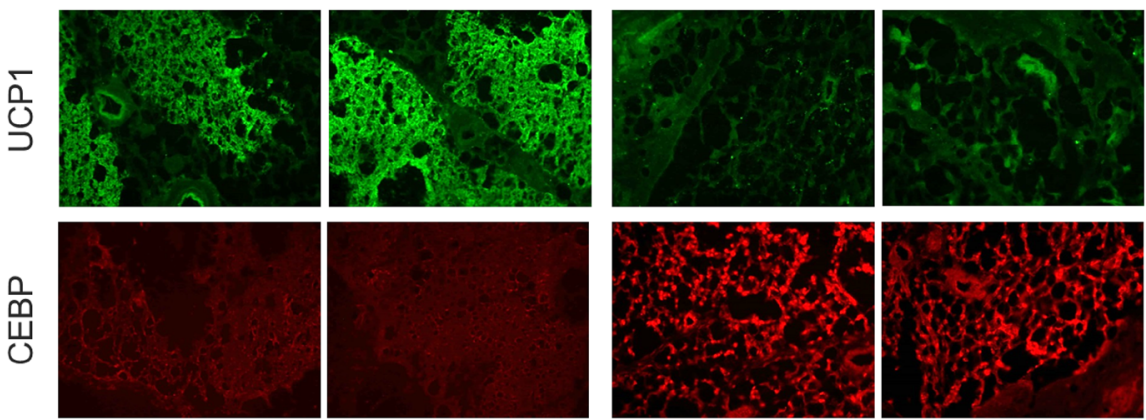
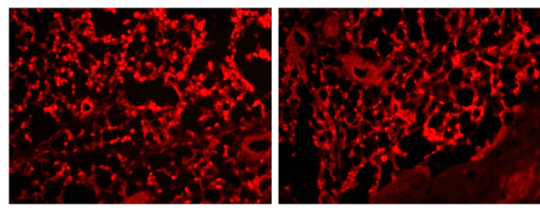
(a) DUhTP
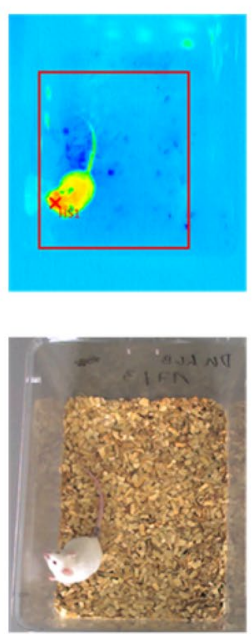

$33.9 \pm 0.54{ }^{\circ} \mathrm{C}$ $28.8 \pm 0.33^{\circ} \mathrm{C}$
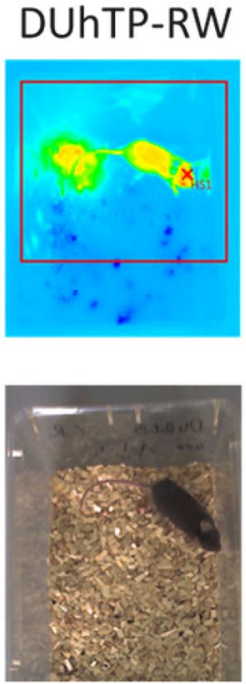

$33.5 \pm 0.90^{\circ} \mathrm{C}$

$28.3 \pm 0.30^{\circ} \mathrm{C}$
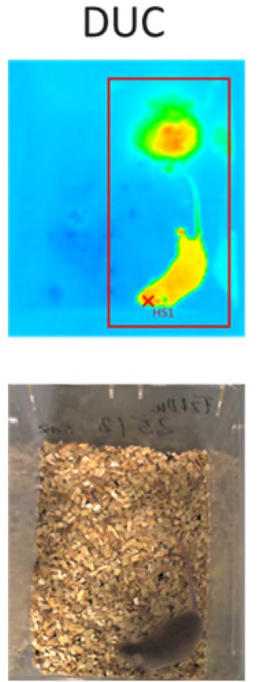

$32.8 \pm 1.35^{\circ} \mathrm{C}$

$28.6 \pm 0.40^{\circ} \mathrm{C}$
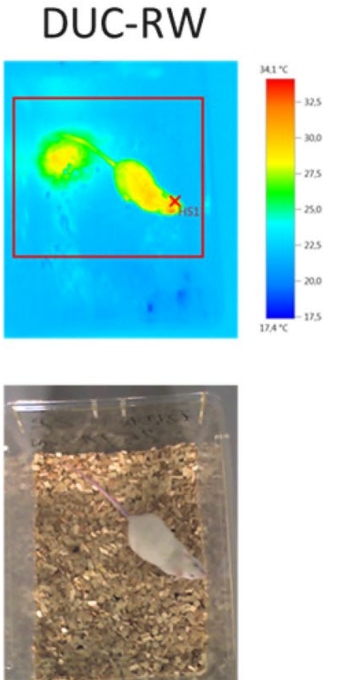

$32.3 \pm 0.85^{\circ} \mathrm{C}$ mean hotspot

$27.5 \pm 0.47{ }^{\circ} \mathrm{C}$ average surface temperature (b)

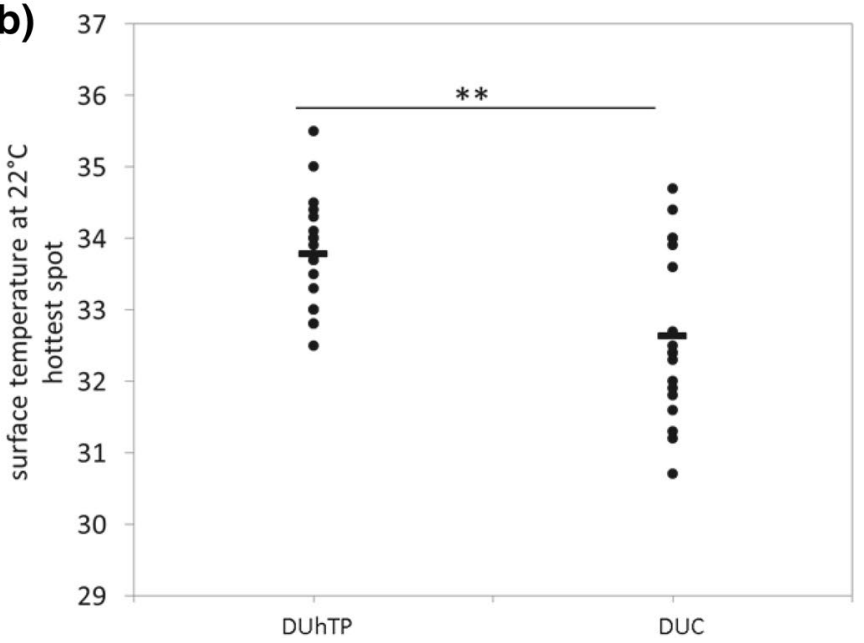

(c)

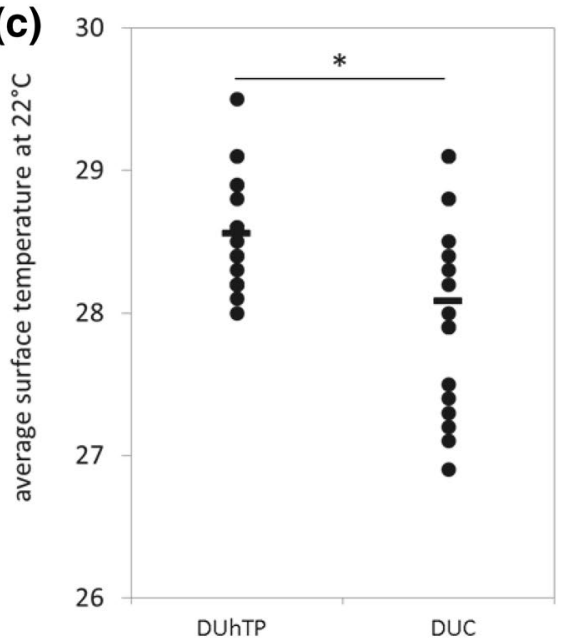

Fig. 4 Analysis of surface temperature of physical active and sedentary DUhTP and DUC mice ( $n=9$ per group). Mice were photographed at $22{ }^{\circ} \mathrm{C}$ using infrared technology (a). Normal photos were taken in parallel. Testo software determined the hottest spot

of Albrecht and coauthors. Barja-Fernandez et al. (2016) could detect a $15 \mathrm{kDa}$ band stained by an irisin antibody that contains indeed no specific peptide signature for irisin. In the present study, higher levels of irisin were observed in serum and subcutaneous adipose tissue of DUhTP mice when compared with controls. However, expression of FNDC5 did not vary between both genotypes in muscle and in subcutaneous fat. Low abundance of FNDC5 protein in subcutaneous fat in contrast to muscular FNDC5 protein is also observed in human studies. Thus, higher local irisin concentrations in subcutaneous fat may be due to transport of muscular-derived irisin to adipose tissue via the blood (b) and the average surface temperature (c) of the mouse. The displayed mouse with according surface temperature is representable for each group-average. Significant differences are indicated: $* P<0.05$; $* * P<0.005$

stream or to enhanced release from other tissues like liver, heart, rectum or brain (Huh et al. 2012). We further cannot exclude the possibility that increased irisin levels arise from enhanced proteolytic cleavage of FNDC5. In response to voluntary activity, changes in FNDC5 expression and irisin levels were not observed in serum or subcutaneous fat when compared to sedentary littermates. Alterations of irisin levels independent of physical activity were only detectable in serum and muscle of our mouse line DUhTP passing a submaximal running test on a treadmill (Brenmoehl et al. 2014). It seems that voluntary physical activity has no influence on irisin level in serum and subcutaneous 
Fig. 5 Oral glucose tolerance tests (oGTT) in male DUhTP and DUC mice under standard chow at an age of 43 days $(\mathbf{a} ; n=20)$ and at an age of 71 days $(\mathbf{b} ; n>5)$. At an age of 43 days for all pairwise comparisons, significant differences were found between DUhTP mice and controls fed standard diet $(P<0.01)$. At an age of 71 days in the presence of running wheels $(\mathrm{RW})$, reduced blood glucose were measured in DUhTP mice if compared to other groups $(* P<0.05)$
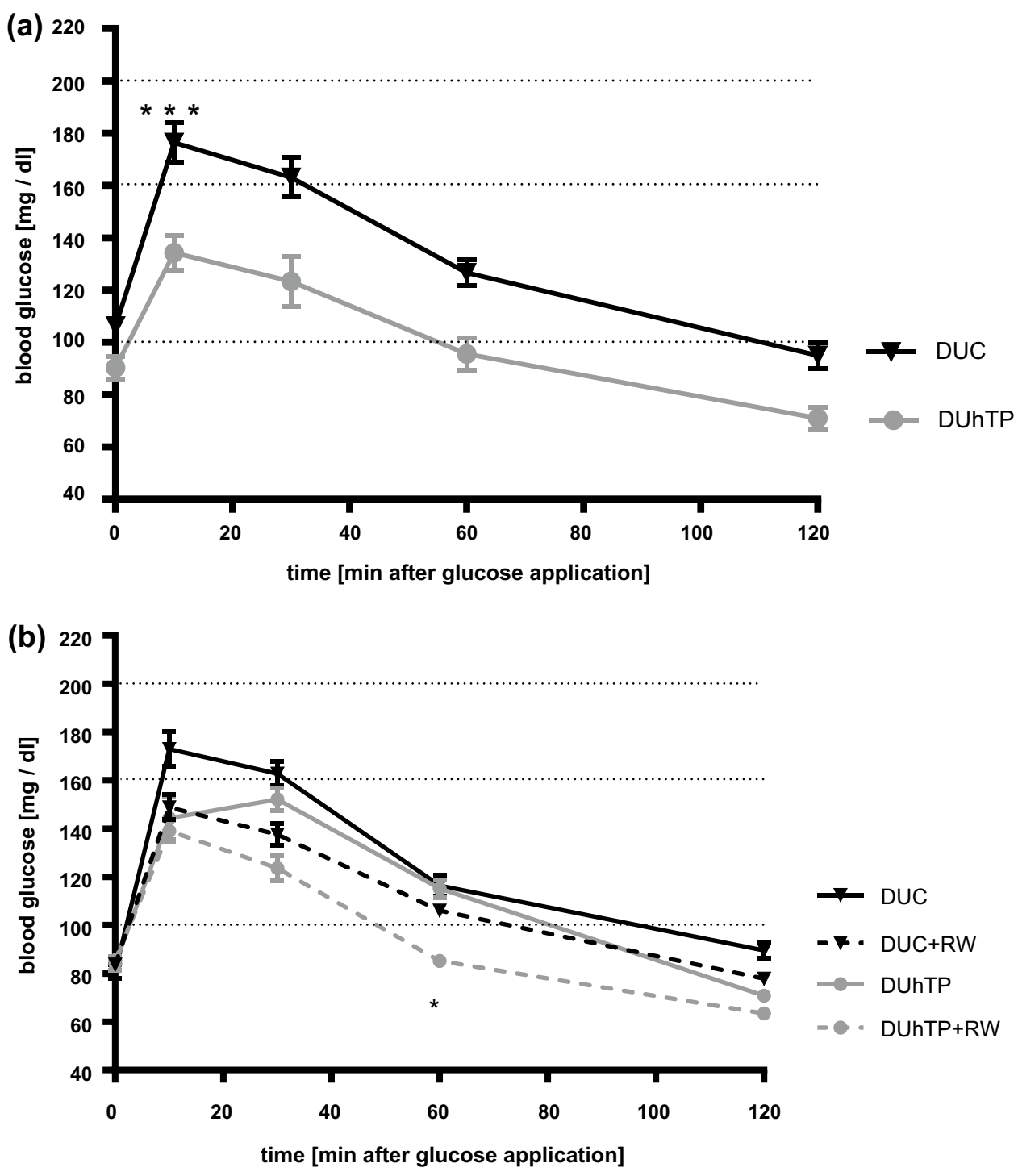

fat in either mouse line but browning of subcutaneous fat as a potential effect of irisin was increased after 3 weeks of moderate exercise.

In cultured skeletal muscle cells, irisin administration results in increased oxidative metabolism and elevated energy expenditure by induction of metabolic genes like PGC1- $\alpha$, Tfam, GLUT4 or UCP3 (Vaughan et al. 2014). In primary cultured rat adipocytes from subcutaneous fat pads a direct administration of recombinant irisin significantly increased gene expression of UCP1 and PGC1- $\alpha$ (Zhang et al. 2014). Daily treatment of normal and obese mice with injection of recombinant irisin for 2 weeks led to elevated levels of Ucp1, Pgc1- $\alpha$, and Ppar $\alpha$ mRNA in subcutaneous fat (Zhang et al. 2014). In mice that were injected with FNDC5-expressing adenovirus, subcutaneous fat pads expressed high levels of Pgc1- $\alpha$ mRNA as well as UCP1 mRNA and protein (Bostrom et al. 2012).
Otherwise, irisin is thought to increase expression of PGC $1-\alpha$ in adipose tissue (Bostrom et al. 2012). We could detect high levels of transcription cofactor PGC1- $\alpha$ mRNA and protein in subcutaneous fat of DUhTP mice compared to unselected controls (Brenmoehl et al. 2015). Additional voluntary exercise resulted in an increase of PGC1- $\alpha$ protein levels. The requirement of PGC1- $\alpha$ to induce acute exercise-mediated Ucp1 mRNA expression in WAT was demonstrated by Ringholm et al. (Ringholm et al. 2013). They found in PGC1- $\alpha \mathrm{KO}$ mice no changes in expression of UCP1 protein in response to exercise training. PGC1- $\alpha$ acts in muscle and adipose tissue as an inducer of mitochondrial biogenesis leading to elevated mitochondrial mass, proteins, and capacity (Lin et al. 2002; Puigserver and Spiegelman 2003; Olesen et al. 2010). DUhTP mice also express high amounts of Tfam, complex I subunits ND1 and NDUFA9, and SIRT3. Voluntary activity 
increased nuclear encoded proteins NDUFA9 and SIRT3 (Brenmoehl et al. 2015), thus implicating higher mitochondrial biogenesis in subcutaneous fat from DUhTP mice associated with higher potential of energy supply.

Detection of substantial irisin levels in subcutaneous fat of DUhTP mice further inspired characterization of adipose tissue of sedentary DUhTP and DUC mice. PPAR $\alpha$, induced by irisin (Huh et al. 2014), is known to induce transcription of UCP1 in adipose tissue (Puigserver 2005) and correlates with the levels of UCP1 (Xue et al. 2005). In the present investigations, high expression levels of both PPAR $\alpha$ and UCP1 in DUhTP mice were identified. Interestingly, positive correlations between Ppar $\alpha$ and Ucp 1 mRNA expression $\left(R^{2}=0.73\right)$ and PPAR $\alpha$ mRNA and UCP1 protein expression $\left(R^{2}=0.61\right)$ were only identified following voluntary activity in DUhTP mice (data not shown). In DUhTP mice, moderate voluntary activity further increased UCP1 levels, which, however, were not reflected by alterations of local irisin concentrations. Thus, we cannot exclude that other mechanisms may contribute to activity-related increases of UCP1 in subcutaneous fat. Precisely, because mitochondrial protein UCP1 uncouples the electron transport chain from energy production, resulting in heat release (Aquila et al. 1985; Argyropoulos and Harper 2002), the surface temperature of both mouse lines was investigated at retained husbandry temperature of $22{ }^{\circ} \mathrm{C}$ without any cold stress. The surface temperature was increased by $1{ }^{\circ} \mathrm{C}$ in DUhTP mice compared to controls. Noninvasive detection of surface temperature by infrared camera identified brown adipose tissue as "hottest spot" of heat production. From the present experiments, it is not clear if core temperature also is increased in DUhTP mice, which can be seen as a limitation of the present study. Subcutaneous fat seems to contribute to higher thermogenesis in DUhTP mice since UCP1 production in brown adipose tissue does not differ between both mouse lines (data not shown). Interestingly, endurance exercise in inbred mice over a period of 6 weeks produced a similar phenotype but in the muscle (Morton et al. 2013). Endurance exercised mice fed a high fat diet were characterized by higher FNDC5, PGC1- $\alpha$, and UCP1 expression and fat cell browning in muscle tissues was discussed in a context of adaptive response to endurance exercise (Morton et al. 2013). While browning in muscle with mitochondrial biogenesis can be interpreted in a context of higher production of energy equivalents, browning and UCP1 production in subcutaneous fat is less clear. On one hand, the activity of UCP1 can be considered as an energyconsuming or even -wasting process. On the other hand, higher surface temperature may also increase biochemical reaction-kinetics associated with endurance performance. To support this idea, again core temperature would have to be assessed in separate studies. The contribution of UCP1 activation and increased surface temperature to physical endurance performance of DUhTP mice needs to be addressed in future studies. At an age of 43 days, DUhTP mice have improved glucose tolerance if fed a normal diet, which is in line with current concepts of metabolic health associated with brown adipose tissues (Stanford et al. 2015). With advanced age improved glucose tolerance is progressively lost in DUhTP mice. Nevertheless, voluntary physical activity maintained improved glucose tolerance at an age of 71 days in DUhTP mice. The reason for the additional increase of UCP1 expression in subcutaneous fat from DUhTP in the presence of running wheels and its specific function for metabolic health is certainly worth of a follow-up study in the future.

To summarize and conclude, the present findings indicate that subcutaneous adipose tissue in DUhTP mice is characterized by increased irisin levels and a substantial browning phenotype if compared to unselected controls. Browning of subcutaneous fat in DUhTP mice includes increased levels of Tbx1, PPAR $\alpha, \mathrm{UCP} 1$, and heat production and correlates with improved oral glucose tolerance at an age of 43 days. While other animal models or humans may exhibit fat cell browning and mitochondrial biogenesis particularly in subcutaneous fat for instance after long and repeated training (Stanford et al. 2015), DUhTP mice have acquired energetic and metabolic adaptations since birth and thus can display fat cell browning in sedentary conditions. Thus, this study demonstrates that the mouse model DUhTP may represent a unique polygenic model for the analysis of mechanism of fat cell browning without previous training, cold exposure or calorie restriction.

Acknowledgments The authors want to thank Luong Chau, Sabine Hinrichs, Stefanie Foß, Dr. Martina Langhammer, Sabine Maibohm, Benita Lucht, Karin Ullerich, Sonja Alm and Magdalene Bülau for excellent technical assistance. Special thanks to Felix Brenmoehl helping us to take infrared photos of our mice using the infrared camera. Andreas Hoeflich and Daniela Ohde were supported by grants from the Deutsche Forschungsgemeinschaft (DFG HO 2003/6-1) and the H. Wilhelm Schaumann Stiftung, respectively. The publication of this article was funded by the Open Access fund of the Leibniz Institute for Farm Animal Biology (FBN).

\section{Compliance with ethical standards}

Conflict of interest All other authors declare no conflicts of interest.

Open Access This article is distributed under the terms of the Creative Commons Attribution 4.0 International License (http://creativecommons.org/licenses/by/4.0/), which permits unrestricted use, distribution, and reproduction in any medium, provided you give appropriate credit to the original author(s) and the source, provide a link to the Creative Commons license, and indicate if changes were made. 


\section{References}

Albrecht E, Kuzinski J, Komolka K, Gotoh T, Maak S (2015a) Localization and abundance of early markers of fat cell differentiation in the skeletal muscle of cattle during growth-are DLK1-positive cells the origin of marbling flecks? Meat Sci 100:237-245. doi:10.1016/j.meatsci.2014.10.012

Albrecht E, Norheim F, Thiede B, Holen T, Ohashi T, Schering L, Lee S, Brenmoehl J, Thomas S, Drevon CA, Erickson HP, Maak $S$ (2015b) Irisin - a myth rather than an exercise-inducible myokine. Sci Rep 5:8889. doi:10.1038/srep08889

Aquila H, Link TA, Klingenberg M (1985) The uncoupling protein from brown fat mitochondria is related to the mitochondrial ADP/ATP carrier. Analysis of sequence homologies and of folding of the protein in the membrane. EMBO J 4(9):2369-2376

Argyropoulos G, Harper ME (2002) Uncoupling proteins and thermoregulation. J Appl Physiol (1985) 92(5):2187-2198. doi:10.1152/japplphysiol.00994.2001

Barja-Fernandez S, Folgueira C, Castelao C, Al-Massadi O, Bravo SB, Garcia-Caballero T, Leis R, Pardo M, Casanueva FF, Seoane LM (2016) FNDC5 is produced in the stomach and associated to body composition. Sci Rep 6:23067. doi:10.1038/srep23067

Bostrom P, Wu J, Jedrychowski MP, Korde A, Ye L, Lo JC, Rasbach KA, Bostrom EA, Choi JH, Long JZ, Kajimura S, Zingaretti MC, Vind BF, Tu H, Cinti S, Hojlund K, Gygi SP, Spiegelman BM (2012) A PGC1-alpha-dependent myokine that drives brown-fat-like development of white fat and thermogenesis. Nature 481(7382):463-468. doi:10.1038/nature10777

Brenmoehl J, Walz C, Renne U, Ponsuksili S, Wolf C, Langhammer M, Schwerin M, Hoeflich A (2013) Metabolic adaptations in the liver of born long-distance running mice. Med Sci Sports Exerc 45(5):841-850. doi:10.1249/MSS.0b013e31827e0fca

Brenmoehl J, Albrecht E, Komolka K, Schering L, Langhammer M, Hoeflich A, Maak S (2014) Irisin is elevated in skeletal muscle and serum of mice immediately after acute exercise. Int $\mathrm{J}$ Biol Sci 10(3):338-349. doi:10.7150/ijbs.7972

Brenmoehl J, Ohde D, Walz C, Schultz J, Tuchscherer A, Rieder F, Renne U, Hoeflich A (2015) Dynamics of fat mass in DUhTP mice selected for running performance-fat mobilization in a walk. Obes Facts 8(6):373-385. doi:10.1159/000442399

Dietl G, Langhammer M, Renne U (2004) Model simulations for genetic random drift in the outbred strain Fzt:DU. Arch Tierzucht 47:595-604

Escher P, Braissant O, Basu-Modak S, Michalik L, Wahli W, Desvergne B (2001) Rat PPARs: quantitative analysis in adult rat tissues and regulation in fasting and refeeding. Endocrinology 142(10):4195-4202. doi:10.1210/endo.142.10.8458

Falkenberg H, Langhammer M, Renne U (2000) Comparison of biochemical blood traits after long-term selection on high or low locomotory activity in mice. Arch Tierzucht 43:513-522

Handschin C, Spiegelman BM (2008) The role of exercise and PGC1alpha in inflammation and chronic disease. Nature 454(7203):463-469. doi:10.1038/nature07206

Himms-Hagen J (1970) Regulation of metabolic processes in brown adipose tissue in relation to nonshivering thermogenesis. Adv Enzyme Regul 8:131-151

Huh JY, Panagiotou G, Mougios V, Brinkoetter M, Vamvini MT, Schneider BE, Mantzoros CS (2012) FNDC5 and irisin in humans: I. Predictors of circulating concentrations in serum and plasma and II. mRNA expression and circulating concentrations in response to weight loss and exercise. Metabolism 61(12):1725-1738. doi:10.1016/j.metabol.2012.09.002

Huh JY, Dincer F, Mesfum E, Mantzoros CS (2014) Irisin stimulates muscle growth-related genes and regulates adipocyte differentiation and metabolism in humans. Int J Obes (2005) 38(12):15381544. doi:10.1038/ijo.2014.42
Lee P, Linderman JD, Smith S, Brychta RJ, Wang J, Idelson C, Perron RM, Werner CD, Phan GQ, Kammula US, Kebebew E, Pacak K, Chen KY, Celi FS (2014) Irisin and FGF21 are cold-induced endocrine activators of brown fat function in humans. Cell Metab 19(2):302-309. doi:10.1016/j.cmet.2013.12.017

Lin J, Wu H, Tarr PT, Zhang CY, Wu Z, Boss O, Michael LF, Puigserver P, Isotani E, Olson EN, Lowell BB, Bassel-Duby R, Spiegelman BM (2002) Transcriptional co-activator PGC-1 alpha drives the formation of slow-twitch muscle fibres. Nature 418(6899):797-801. doi:10.1038/nature00904

Mo L, Shen J, Liu Q, Zhang Y, Kuang J, Pu S, Cheng S, Zou M, Jiang W, Jiang C, Qu A, He J (2016) Irisin is regulated by CAR in liver and is a mediator of hepatic glucose and lipid metabolism. Mol Endocrinol (Baltim, Md) 30(5):533-542. doi:10.1210/ me.2015-1292

Morton TL, Styner M, Rubin JE (2013) Running increases and alters intramyocellular lipid phenotype. Paper presented at the annual meeting of the Endocrine Society, San Francisco

Olesen J, Kiilerich K, Pilegaard H (2010) PGC-1alpha-mediated adaptations in skeletal muscle. Pflugers Arch 460(1):153-162. doi:10.1007/s00424-010-0834-0

Puigserver P (2005) Tissue-specific regulation of metabolic pathways through the transcriptional coactivator PGC1-alpha. Int J Obes (Lond) 29(Suppl 1):S5-S9. doi:10.1038/sj.ijo.0802905

Puigserver P, Spiegelman BM (2003) Peroxisome proliferator-activated receptor-gamma coactivator 1 alpha (PGC-1 alpha): transcriptional coactivator and metabolic regulator. Endocr Rev 24(1):78-90. doi:10.1210/er.2002-0012

Renne U, Langhammer M, Brenmoehl J, Walz C, Zeissler A, Tuchscherer A, Piechotta M, Wiesner RJ, Bielohuby M, Hoeflich A (2013) Lifelong obesity in a polygenic mouse model prevents age- and diet-induced glucose intolerance- obesity is no road to late-onset diabetes in mice. PLoS One 8(11):e79788. doi:10.1371/journal.pone.0079788

Ringholm S, Grunnet KJ, Leick L, Lundgaard A, Munk NM, Pilegaard H (2013) PGC-1alpha is required for exercise- and exercise training-induced UCP1 up-regulation in mouse white adipose tissue. PLoS One 8(5):e64123. doi:10.1371/journal. pone. 0064123

Roca-Rivada A, Castelao C, Senin LL, Landrove MO, Baltar J, Belen Crujeiras A, Seoane LM, Casanueva FF, Pardo M (2013) FNDC5/irisin is not only a myokine but also an adipokine. PLoS One 8(4):e60563. doi:10.1371/journal.pone.0060563

Ruas JL, White JP, Rao RR, Kleiner S, Brannan KT, Harrison BC, Greene NP, Wu J, Estall JL, Irving BA, Lanza IR, Rasbach KA, Okutsu M, Nair KS, Yan Z, Leinwand LA, Spiegelman BM (2012) A PGC-1alpha isoform induced by resistance training regulates skeletal muscle hypertrophy. Cell 151(6):1319-1331. doi:10.1016/j.cell.2012.10.050

Stanford KI, Middelbeek RJ, Goodyear LJ (2015) Exercise effects on white adipose tissue: beiging and metabolic adaptations. Diabetes 64(7):2361-2368. doi:10.2337/db15-0227

Taylor SC, Berkelman T, Yadav G, Hammond M (2013) A defined methodology for reliable quantification of Western blot data. Mol Biotechnol 55(3):217-226. doi:10.1007/ s12033-013-9672-6

Vaughan RA, Gannon NP, Barberena MA, Garcia-Smith R, Bisoffi M, Mermier CM, Conn CA, Trujillo KA (2014) Characterization of the metabolic effects of irisin on skeletal muscle in vitro. Diabetes Obes Metab 16(8):711-718. doi:10.1111/dom.12268

Wu J, Bostrom P, Sparks LM, Ye L, Choi JH, Giang AH, Khandekar M, Virtanen KA, Nuutila P, Schaart G, Huang K, Tu H, van Marken Lichtenbelt WD, Hoeks J, Enerback S, Schrauwen P, Spiegelman BM (2012) Beige adipocytes are a distinct type of thermogenic fat cell in mouse and human. Cell 150(2):366-376. doi:10.1016/j.cell.2012.05.016 
Xue B, Coulter A, Rim JS, Koza RA, Kozak LP (2005) Transcriptional synergy and the regulation of Ucp1 during brown adipocyte induction in white fat depots. Mol Cell Biol 25(18):83118322. doi:10.1128/MCB.25.18.8311-8322.2005

Zhang Y, Li R, Meng Y, Li S, Donelan W, Zhao Y, Qi L, Zhang M, Wang X, Cui T, Yang LJ, Tang D (2014) Irisin stimulates browning of white adipocytes through mitogen-activated protein kinase p38 MAP kinase and ERK MAP kinase signaling. Diabetes 63(2):514-525. doi:10.2337/db13-1106
Zhang Y, Xie C, Wang H, Foss RM, Clare M, George EV, Li S, Katz A, Cheng H, Ding Y, Tang D, Reeves WH, Yang LJ (2016) Irisin exerts dual effects on browning and adipogenesis of human white adipocytes. Am J Physiol Endocrinol Metab 311(2):E530 E541. doi:10.1152/ajpendo.00094.2016 